\title{
Modeling Managerial Accounting Information Systems Acceptance and Intention of Retention: Activity based Costing System as an Example
}

\author{
AHMED ABDULLAH SAAD AL-DHUBAIBI \\ Department of Accounting \\ College of Business Administration \\ Prince Sattam Bin Abdulaziz University, SAUDI ARABIA
}

\begin{abstract}
Accounting information systems acceptance and use has been a research interest for many researchers in recent years. Research in this area has employed several models related to technology acceptance and adoption. Factors that influence users' acceptance and intention of use were investigated based on the preimplementation perception of users regarding the usefulness of the systems, ease of use, and many other factors. In contrast, this study provides evidence on the post-implementation acceptance of the Activity-Based Costing (ABC) information system as a result of familiarity with the system and the realized benefits rather than expected. A questionnaire survey is used for data collection from different sized manufacturing companies. To analyze the hypothesized model, data obtained from non-adopters of ABC or adopters at the early stage of adoption were excluded from the analysis. In total, 83 valid responses were collected and used in the analysis. The findings indicate that user acceptance of $\mathrm{ABC}$ as a managerial accounting information system was enforced by the wider extent of use and the mediation of reported benefits that were realized by users (departments) of the system. Further, the acceptance of the system mediates the extent of use and the magnitude of reported benefits in their positive effect on the organizational intention to retain the system. These results guide companies that establish a new accounting information system, which may encounter a certain level of resistance, to make the benefits of the system implementation visible to all departments to create acceptance for the system and maximize the benefits of its use.
\end{abstract}

Key-words: Accounting Information Systems, Activity Based Costing, Acceptance, Intention of Retention, Extent of Use, Benefits.

Received: April 28, 2021. Revised: November 1, 2021. Accepted: November 12, 2021. Published: November 30, 2021.

\section{Introduction}

Understanding the attitudes of the accounting information system prospective users is crucial. Mandating the use of an information system such as ERP may result in resistance, dissatisfaction, and low morale of the system users [1]. Potential consequences of user resistance could be noticed in reduced work quality and productivity at the organizational level which may lead, in some circumstances, to the fail of the information system project implementation [2]. Nevertheless, the majority of research on information systems acceptance was conducted on voluntary settings even though in most organizations, users have minimal discretion to choose to use or not to use the system [3]. The responses of the potential users to a mandated information system could vary from the engagement and compliance response to reluctance or deviation [1]. The identification of the influential factors to the information systems users' acceptance or resistance in the early stages of implementation facilitates the success of the system and optimizes its implementation value [4]. However, there is a lack of research on the influential factors of mandated information systems users' compliance [5]. Research on information systems adoption indicated that user resistance is a major concern for companies' management [6, 7]. Researchers, therefore, have paid considerable attention to the causes of user resistance and the possible ways to reduce the threats of resistance [8].

Activity-Based Costing ( $\mathrm{ABC}$ ) is a costing and performance management tool which enables companies to determine the products and services' cost based on the cost of activities using smart cost drivers. It has been argued that the ABC system provides accurate and relevant information for decision-making and performance measurement $[9$, 10]. ABC facilitates the management's efforts of reducing costs, identifying and eliminating nonvalue-added activities, and eventually improving 
organizational performance [11]. Research that investigated the motives of $\mathrm{ABC}$ adoption and implementation revealed that the unreliability of the traditional costing system and its inability to meet the needs of management are the most obvious reasons for $\mathrm{ABC}$ adoption [12]. In the survey of Innes and Mitchell [13], UK firms have reported various usage and benefits from ABC. Firms have used cost drivers statistics in predicting future resource needs and setting more realistic budgets. $\mathrm{ABC}$ adopters have used the $\mathrm{ABC}$ technique for budgeting, pricing decisions, and performance measurement. Performance measures of activities' costs, cost driver volumes, and cost driver rates were used to evaluate performance efficiency, effectiveness, and quality. However, managerial innovations that make changes and improve the information provided to managers usually encounter organizational resistance. Such resistance has encountered the change to the ABC system [14]. Attitudes of individuals towards the cost management system change depend on the harmony between the system and the change they desire to make. To overcome such resistance, firms should align the change caused by the system with the individual objectives and organizational strategy $[15,16]$.

Prior research on the acceptance and usage of accounting information systems has followed the technology acceptance and use research that proposes several models such as Unified Theory of Acceptance and Use of Technology (UTAUT) and Technology Acceptance Model (TAM). These models depend mainly on the adoption and acceptance theories such as Theory of Reasoned Action (TRA), Social Cognitive Theory (SCT), and Diffusion of Innovations Theory (DOI). However, adoption theories and acceptance models explain the acceptance of users and their intention to use the accounting systems through pre-implementation factors that relate to the perception of users about the system that is yet to be used. For instance, Lee, Yen [17] used the UTAUT model to explain the change agents' (decision-makers) behavioral intention influence on the usage of the $\mathrm{ABC} / \mathrm{M}$ system. According to their hypothesized model, the behavioral intention of the change agent is influenced by performance expectancy, efforts expectancy, and social influence.

It can be noticed that previous research has not paid enough attention to the post-implementation factors that affect the acceptance level of accounting information systems. This study contributes to the literature in different ways; first, it investigates the post-implementation acceptance of $\mathrm{ABC}$ as an accounting system based on user experience rather than perception. Second, this study explains the acceptance of the ABC system on an organizational level through department-wise acceptance (rather than individual user) with a focus on the nonfinancial departments' acceptance and top management decision to retain the system. Finally, this study investigates the acceptance and use of $\mathrm{ABC}$ as an accounting information system apart from technological aspects that are associated with general technology acceptance issues.

\section{Literature Review and Hypotheses Development}

Since the early $90 \mathrm{~s}$, a considerable number of studies and surveys have been conducted in developed and developing countries to explore the rate of $\mathrm{ABC}$ adoption within companies. Most of these studies have presented the views of $A B C$ users and non-users about $\mathrm{ABC}$ usefulness, efficiency, applicability, applications by users, and the degree of success of $\mathrm{ABC}$ implementation. Innes and Mitchell [13] surveyed the largest 1000 U.K. companies and found that among the usable responses the percentage of $\mathrm{ABC}$ adopters is only $20 \%$. Innes, Mitchell [18] made another survey on the largest U.K. companies. Their results showed no important difference in the companies' interest in $A B C$. They did not find any increase in $A B C$ adopters between 1994 and 1999. On the contrary, the percentage of $\mathrm{ABC}$ adopters has fallen from 20 percent to 17.5 percent and the percentage of firms considering using $\mathrm{ABC}$ in the future has fallen from 29.5 percent in 1994 to 20.3 percent in 1999. Despite the results of the new survey showed a decrease of overall $\mathrm{ABC}$ adopters to 17.5 percent, the adoption of $\mathrm{ABC}$ by the largest companies has increased considerably to 32.8 percent. The situation in the United States was not different as a survey on the use of $\mathrm{ABC}$ in the government sector particularly in large U.S. cities showed similar results. Research findings indicated that currently $\mathrm{ABC}$ is not widely used and there is no probability in the future to be widely used by U.S. large cities [19]. In Japan, Souissi [20] has undertaken a study to explore how $A B C$ was perceived by Japanese firms. He concluded that the concept of cost drivers brought by $\mathrm{ABC}$ was perceived favorably by Japanese firms as a tool for continuous improvement despite the low adoption rate. Japanese firms have advanced accounting systems such as target costing, kaizen costing, and value engineering. $\mathrm{ABC}$ requirements overlap with the requirements of those 
techniques which might explain the low adoption rate of ABC in Japan. Cohen, Venieris [21] studied the ABC adoption in Greece. Their survey targeted companies from the main sectors of the Greek economy namely; manufacturing, retail, and services. Their results showed a 40.9 percent adoption rate of $\mathrm{ABC}$ by Greek firms. The rest of the firms were divided into three categories which are $\mathrm{ABC}$ supporters (13.6 percent), $\mathrm{ABC}$ unawares (13.6 percent), and $\mathrm{ABC}$ deniers (31.9 percent). In Malaysia, 2006 survey results showed $36 \%$ of Malaysian firms in the sample have adopted $\mathrm{ABC}$ [22].

When the objectives of $\mathrm{ABC}$ are clear to all parties involved in the system implementation and the consensus about its usefulness and importance exist, employees and their supervisors will enhance teamwork and cooperate effectively towards ABC's successful implementation. Consensus about and clarity of objectives results in an improved design of the ABC system and a better usage of its outputs [23]. There is a positive and significant relationship between the clarity of objectives as a part of behavioral implementation factors and the usefulness of $\mathrm{ABC}$ [24]. Companies that segregate their business such as sales, purchase, and production to separate entities have a high probability of unsuccessful implementation of $A B C$ due to objectives asymmetry and an unclear purpose of the system [25]. In the survey of Innes and Mitchell [13], UK firms have reported various usage and benefits from ABC. Firms have used cost drivers statistics in predicting future resource needs and setting more realistic budgets. $60 \%$ of $\mathrm{ABC}$ adopters have used the $\mathrm{ABC}$ technique for budgeting successfully. $66 \%$ of $\mathrm{ABC}$ users have used $\mathrm{ABC}$ in pricing decisions and $12 \%$ intended to use it for pricing in the future. Maiga and Jacobs [26] in their study (extent of ABC use and its consequences) found no significant direct association between the extent of $\mathrm{ABC}$ use and manufacturing profitability. Rather, they found a positive and significant relationship between the extent of $\mathrm{ABC}$ use and profitability indirectly through the intervening variables of plant operational performance named; improved quality, cycle time, and cost. Accordingly, the following hypotheses are developed;

$$
\begin{aligned}
& \text { H1: The extent of ABC use has a positive } \\
& \text { and significant effect on the } \\
& \text { magnitude of } A B C \text { benefits reported } \\
& \text { by adopters. }
\end{aligned}
$$

\section{H2: The magnitude of ABC benefits has a positive and significant effect on the intention of $A B C$ adopters to retain the system.}

\section{H3: The magnitude of ABC benefits mediates the relationship between the extent of $A B C$ use and the intention to retain the system.}

Technology Acceptance Model attributes the acceptance of a new information system and the behavioral intention of using it to the perceived usefulness of the system and perceived ease of use [27] with a positive association between the perceived ease of use and the perceived usefulness [28]. Further, the perceived usefulness of the system influences the user's behavioral intention to use the system $[29,30]$.

$\mathrm{ABC}$ implementation success requires the involvement of non-accounting personnel in designing the project, gathering data, and using information for decision making. Therefore, nonaccounting ownership is essential for the system's success [31]. Non-accounting managers' involvement will help in reducing their personnel resistance and secure commitment by their employees [14]. Major and Hopper [32] in their case study on the Portuguese telecommunications company reported the contradiction between production engineers' attitudes towards the $\mathrm{ABC}$ system and commercial managers. Production personnel was reluctant to use $\mathrm{ABC}$ and have difficulties understanding the system while commercial personnel uses $\mathrm{ABC}$ information in decision making such as pricing and they expressed their satisfaction with the system. The disagreement about the system's usefulness and importance creates problems and challenges that constrained the success of the ABC system and limited its usefulness. The $\mathrm{ABC}$ team composition should be cross-functional and should include employees from various departments to help in sharing experience and knowledge within the team [33]. Therefore, the following hypotheses are developed:

H4: The magnitude of ABC benefits has a positive and significant effect on user acceptance of the system.

\section{H5: The magnitude of $A B C$ benefits mediates the relationship between the extent of $A B C$ use and user acceptance of the system.}


Successful implementation of any accounting information system is dependent on the personnel commitment to using the system $[34,35]$. This finding explains why the declared realized benefits of Enterprise Resource Planning (ERP) systems by US companies are significantly less than preimplementation estimated benefits [36]. Users of the accounting information system may have a negative attitude towards the system but still be required to use it when the decision of adoption is made by the top management. In such cases, mandating the implementation of the system may result in underuse, frustration, and ambivalence [5].

Narayanan and Sarkar [37] stated that in many cases of $\mathrm{ABC}$ implementation, the information produced by the $\mathrm{ABC}$ system did not affect the managerial decisions due to the organizational resistance. Innes and Mitchell [13] found that 41\% of $\mathrm{ABC}$ users reported some resistance by their employees. Employees resisted ABC because they thought its information will be used to reduce cost through staff redundancy. Moreover, they did not like the accountability that may result from activity analysis. The reservation about $\mathrm{ABC}$ usefulness has been reported not only by employees but also by managers [21] who thought they will lose some of their power to other departments or they will lose their jobs in the end, if the $\mathrm{ABC}$ system to be implemented [38].

Moreover, the change from a management system to another (i.e. adopting an innovation such as $A B C$ ) could encounter many other barriers to the implementation of the innovation [14]. Despite a large number of researches and studies about $\mathrm{ABC}$ and the detailed technical steps of its implementation that have been explained by academicians and practitioners, still, some organizations have difficulties and encounter challenges in implementing the system [21]. Respondents on the survey of Innes, Mitchell [18] stated that the complexity of the system and its operating requirements will make the cost of $\mathrm{ABC}$ implementation exceed its benefits. The strategy should attempt to influence the perspective of those participants who resist the changes by participation in educational programs designed to establish awareness about the change's advantages and outcomes [14]. The degree of ABC implementation success is associated with a greater extent of use and more reported benefits [39]. Consequently, the following hypotheses are developed:

H6: User acceptance of the ABC system has a positive and significant effect on the intention of $A B C$ adopters to retain the system.

H7: User acceptance of the ABC system mediates the relationship between the magnitude of $A B C$ benefits and the intention to retain the system.
H8: The extent of $A B C$ use has a positive and significant effect on user acceptance of the system.
H9: User acceptance of the $A B C$ system mediates the relationship between the extent of $A B C$ use and the intention to retain the system.

\section{Methodology}

This study aims to understand the influential factors of $\mathrm{ABC}$ accounting system acceptance by various finance and non-finance departments in manufacturing companies. Further, the study examines how the collective departmental acceptance of the $A B C$ system affects the decision of the concerned management level to retain the system and keep using it in the future. For this purpose, the manufacturing companies in Riyadh province were identified as the population of the sample for this study as the significant portion of the industry in Saudi Arabia is concentrated in this geographical area. The questionnaire survey was sent to the manufacturing companies to collect empirical data from $\mathrm{ABC}$ adopters. In total, 83 valid responses were collected. An instructional statement was placed at the top of the questionnaire stating that the questionnaire is aimed only at companies that are implementing the $\mathrm{ABC}$ system. Non-adopters of $\mathrm{ABC}$ were excluded from the sample. The restriction of the questionnaire to the $\mathrm{ABC}$ adopters only is aimed to obtain observed facts regarding the actual use of the ABC system in various organizational activities and the realized and measured benefits for its implementation.

The questionnaire encompasses four sections. The first two sections ask the respondents to state the current situation of $\mathrm{ABC}$ implementation with regards to its extent of use within different types and levels of organizational activities and the reported 
benefits of $\mathrm{ABC}$ implementation that are realized by various departments. The third section of the questionnaire explores the level of acceptance of the $\mathrm{ABC}$ system by financial and non-financial departments according to the perception of the respondent. The fourth section aimed to probe the plan of the company to keep using the $\mathrm{ABC}$ system in the future (intention to retain the system). A five-point Likert Scale is used in which " $1=$ strongly disagree and $5=$ strongly agree". The items that are intended to measure the extent of $\mathrm{ABC}$ use and the magnitude of its benefits are structured to capture the several organizational activities that are using $\mathrm{ABC}$ and benefits that are obtained by different departments of the companies. Items that are aimed to measure the acceptance of $\mathrm{ABC}$ prepared to capture the acceptance of the system by the financial and non-financial departments. In other words, the items intended to measure these variables are cumulative measures and not reflective items of a construct. Accordingly, the items' values of each variable were added using the compute function of the SPSS software and used as one collective value. The intention to retain the system variable was measured using a single item (question). Therefore, the variables of this study were analyzed as observed variables in the path analysis. The discriminant validity of the variables was examined using the covariance analysis of AMOS software. The estimate values of correlations are presented in Table 1. Since the correlations are all $<0.6$, the discriminant validity of the model has been achieved.

Table 1. Discriminant Validity Index Summary (correlation between measurement model constructs)

\begin{tabular}{rrlr}
\hline Construct & Path & Construct & Estimate \\
\hline ABC Benefits & <--> & Extent of & Use \\
Extent of Use & $<-->$ & Acceptance & .578 \\
Extent of Use & $<-->$ & $\begin{array}{l}\text { Intention to } \\
\text { retain ABC }\end{array}$ & .370 \\
ABC Benefits & $<-->$ & $\begin{array}{l}\text { Acceptance } \\
\text { ABC Benefits }\end{array}$ & .573 \\
& & $\begin{array}{l}\text { Intention to } \\
\text { retain ABC }\end{array}$ & .432
\end{tabular}

Table 1. Discriminant Validity Index Summary (correlation between measurement model constructs)

\begin{tabular}{rrrr}
\hline Construct & Path & Construct & Estimate \\
\hline Acceptance & $<-->$ & $\begin{array}{r}\text { Intention to } \\
\text { retain ABC }\end{array}$ & .536 \\
\hline
\end{tabular}

\section{Results}

The structural equation modeling analysis is performed in two phases to test the hypothesized relationships of the proposed model. The first phase of analysis tests the primary model (figure 1) hypotheses. In this phase, AMOS structural model is run to test for the effect of Extent of ABC Use on the companies' Intention to Retain the System with the mediating role of Reported ABC Benefits (Hypotheses 1-3). The second phase of analysis encompasses Users Acceptance of the System as the main mediator of the comprehensive model. In this phase, three triangulated relationships were identified with a mediating variable in each and the User Intention to Retain the System as the ultimate dependent variable (figure 2).

\subsection{The Primary Model}

Figure 1 and Table 2 present the results of the hypothesized primary model in which Reported $\mathrm{ABC}$ benefits mediates the relationship between the Extent of ABC Use and User Intention to Retain the System. Figure 1 displays the standardized regression weight for the hypothesized relationships and the squared multiple correlations $\left(\mathrm{R}^{2}\right)$ for the endogenous variables in the model. Table 2 presents; first, a summary of the standardized beta estimates of the effects of the exogenous variable on the endogenous variables; second, the regression weights for the effect of each exogenous variable on each endogenous variable with a summary of the actual beta estimates (Estimate), standard error (S.E.), critical ratio (C.R.), and the level of significance (P-value); third, a summary of the steps involved in testing the mediating effect of Reported $\mathrm{ABC}$ Benefits on the relationship between Extent of $\mathrm{ABC}$ Use and User Intention to Retain the System.

\subsubsection{The Direct Effects}

Summarized standardized beta estimates in Table 2 show how the endogenous variables change when the exogenous variables change by standardized values. These standardized values show that when the Extent of ABC Use goes up by (1) standard deviation, $\mathrm{ABC}$ Reported Benefits goes up by 
(0.578) standard deviations. Furthermore, when ABC Reported Benefits goes up by (1) standard deviation, Intention to Retain $\mathrm{ABC}$ goes up by (0.307) standard deviations.

Figure 1 presents the squared multiple correlations $\left(\mathrm{R}^{2}\right)$ for the endogenous variables in the model that are ABC Reported Benefits (0.334) and Intention to Retain $\mathrm{ABC}(0.218)$. It is estimated that the predictor(s) of $\mathrm{ABC}$ Reported Benefits explain (33.4) percent of its variance and the predictor(s) of Intention to Retain $\mathrm{ABC}$ explain (21.8) percent of its variance.

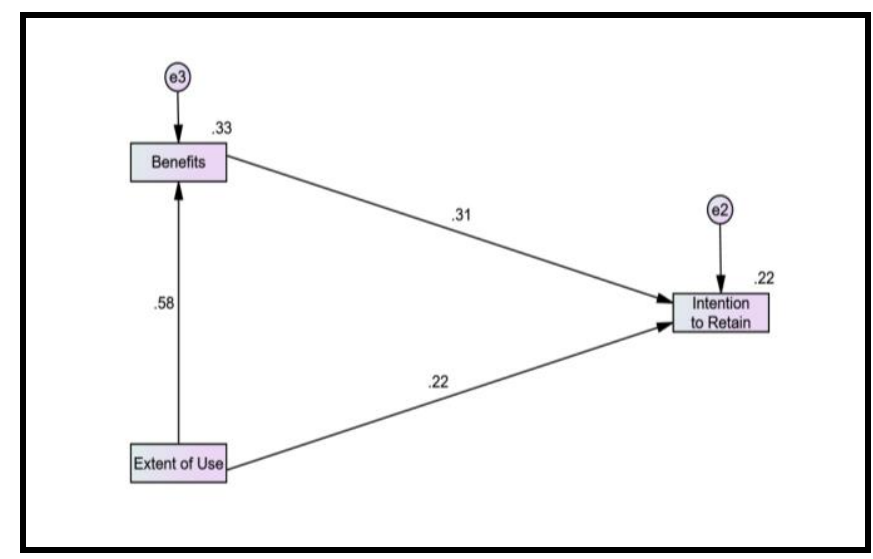

Fig. 1: The Standardized Regression Weights for the Primary Model

Table 2 also summarizes the actual beta estimates of the effect of extent of ABC Use on the magnitude of $\mathrm{ABC}$ reported benefits (1.326) and the effect of $A B C$ reported benefits on user intention to retain $\mathrm{ABC}(0.033)$. The actual beta estimates show that when the Extent of $\mathrm{ABC}$ Use goes up by (1), ABC Reported Benefits goes up by (1.326), and when $\mathrm{ABC}$ Reported Benefits goes up by (1), Intention to Retain $\mathrm{ABC}$ goes up by (0.033).

The regression weight estimate for the effect of Extent of $\mathrm{ABC}$ Use on $\mathrm{ABC}$ Reported Benefits has a standard error of about (0.238) and a critical ratio of (5.572). The P-Value indicates that the effect of
Extent of $\mathrm{ABC}$ Use on $\mathrm{ABC}$ Reported Benefits is significant at $P<0.001$ (The probability of getting a critical ratio as large as 5.572 in absolute value is less than 0.001). In other words, the regression weight for Extent of $\mathrm{ABC}$ Use in the prediction of ABC Reported Benefits is significantly different from zero at the 0.001 level (two-tailed). Therefore, Hypothesis (1) is supported.

The regression weight estimate for the effect of $\mathrm{ABC}$ Reported Benefits on Intention to Retain $\mathrm{ABC}$ has a standard error of about (0.015) and a critical ratio of 2.228 . The P-Value indicates that the effect of $\mathrm{ABC}$ Reported Benefits on Intention to Retain $\mathrm{ABC}$ is significant at $P<0.05$ (The probability of getting a critical ratio as large as 2.228 in absolute value is (0.026). In other words, the regression weight for $\mathrm{ABC}$ Reported Benefits in the prediction of Intention to Retain $A B C$ is significantly different from zero at the 0.05 level (two-tailed). Hence, the results support Hypothesis (2).

\subsubsection{The Indirect (Mediating) Effect}

The results presented in Table 2 illustrate that the direct effect of Extent of $\mathrm{ABC}$ Use on the Intention to Retain $\mathrm{ABC}$, before the inclusion of the mediator to the model is significant. The P-Value of the direct effect is significant at $P<0.001$. When the mediator is inserted into the model, the direct effect is reduced and becomes insignificant, $P=0.116$, implying that the regression weight is not significantly different from zero at the 0.05 level (two-tailed). Given both indirect paths; Extent of ABC Use on Reported ABC Benefits $(P<0.001)$ and Reported $\mathrm{ABC}$ Benefits on Intention to retain $\mathrm{ABC}$ $(P<0.05)$ are significant, the conditions of the full mediations have been met and Hypothesis (3) is supported. 
Table 2. Reported ABC Benefits mediating the effect of "Extent of ABC Use" on the "Intention to retain ABC"

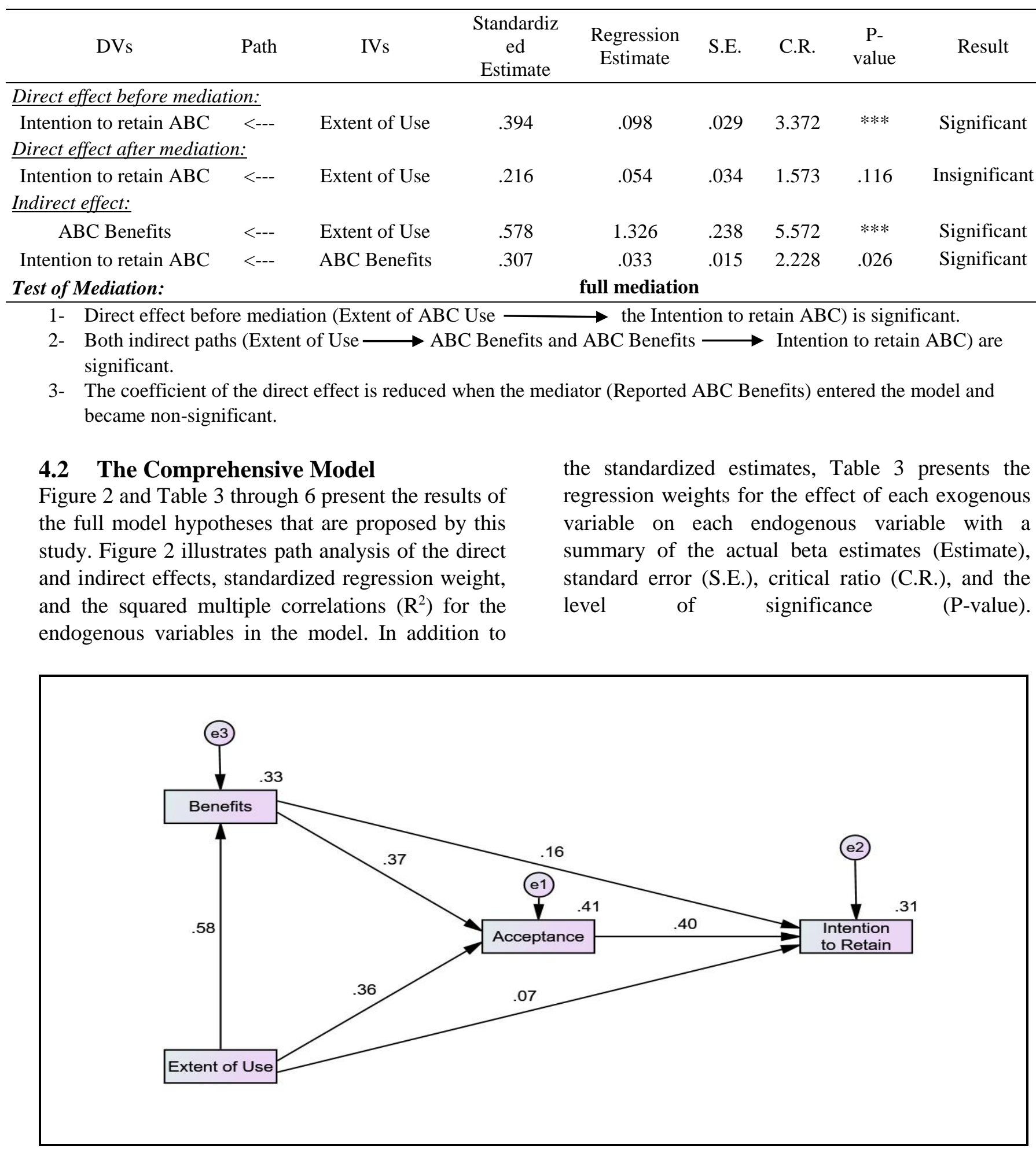

Fig. 2: The Standardized Regression Weights for the Full Mediated Model

\subsubsection{The Magnitude of ABC Benefits Mediates the Effect of Extent of ABC Use on User Acceptance of the System}

The effect of Extent of ABC Use on ABC Reported Benefits has been established in the primary model and discussed in an earlier section. The results of this effect that is obtained from the comprehensive model are identical to those obtained from the primary model. Table 3 presents the standardized beta estimates of the effect of $\mathrm{ABC}$ Reported 
Benefits on User Acceptance which indicates that when ABC Reported Benefits goes up by 1 standard deviation, User Acceptance goes up by 0.367 standard deviations. Furthermore, the actual beta estimates show that when ABC Reported Benefits goes up by 1 , User Acceptance goes up by 0.124 .

Table 3. The standardized Regression Weights \& Regression Weights for the Full Mediated Model

\begin{tabular}{ccccccccc}
\hline \multirow{2}{*}{ Construct } & Path & Construct & $\begin{array}{c}\text { Standardiz } \\
\text { ed } \\
\text { Estimate }\end{array}$ & $\begin{array}{c}\text { Regression } \\
\text { Estimate }\end{array}$ & S.E. & C.R. & $\begin{array}{c}\text { P- } \\
\text { value }\end{array}$ & Result \\
\hline ABC Benefits & $<---$ & Extent of Use & .578 & 1.326 & .238 & 5.572 & $* * *$ & Significant \\
Acceptance & $<---$ & ABC Benefits & .367 & .124 & .040 & 3.078 & .002 & Significant \\
Acceptance & $<---$ & Extent of Use & .358 & .278 & .092 & 3.005 & .003 & Significant \\
Intention to retain ABC & $<---$ & Acceptance & .403 & .130 & .044 & 2.934 & .003 & Significant \\
Intention to retain ABC & $<---$ & ABC Benefits & .159 & .017 & .015 & 1.147 & .251 & Insignificant \\
Intention to retain ABC & $<---$ & Extent of Use & .072 & .018 & .034 & .522 & .602 & Insignificant \\
\hline
\end{tabular}

The regression weight estimate for the effect of ABC Reported Benefits on User Acceptance has a standard error of about (0.040) and a critical ratio of (3.078). The P-Value indicates that the effect of ABC Reported Benefits on User Acceptance is significant at $P<0.01$ (The probability of getting a critical ratio as large as 3.078 in absolute value is 0.002). In other words, the regression weight for $\mathrm{ABC}$ Reported Benefits in the prediction of User Acceptance is significantly different from zero at the 0.01 level (two-tailed). Accordingly, the results support Hypothesis

(4).

Table 4. Reported ABC Benefits mediating the effect of "Extent of ABC Use" on the "Acceptance"

\begin{tabular}{|c|c|c|c|c|c|c|c|c|}
\hline DVs & Path & IVs & $\begin{array}{c}\text { Standardiz } \\
\text { ed } \\
\text { Estimate }\end{array}$ & $\begin{array}{c}\text { Regression } \\
\text { Estimate }\end{array}$ & S.E. & C.R. & $\begin{array}{c}\mathrm{P}- \\
\text { value }\end{array}$ & Result \\
\hline \multicolumn{9}{|c|}{ Direct effect before mediation: } \\
\hline Acceptance & $<--$ & Extent of Use & .570 & .442 & .081 & 5.457 & $* * *$ & Significant \\
\hline \multicolumn{9}{|c|}{ Direct effect after mediation: } \\
\hline Acceptance & $<--$ & Extent of Use & .358 & .278 & .092 & 3.005 & .003 & Significant \\
\hline \multicolumn{9}{|l|}{ Indirect effect: } \\
\hline ABC Benefits & $<--$ & Extent of Use & .578 & 1.326 & .238 & 5.572 & $* * *$ & Significant \\
\hline Acceptance & $<--$ & ABC Benefits & .367 & .124 & .040 & 3.078 & .002 & Significant \\
\hline Test of Mediation: & \multicolumn{8}{|c|}{ Partial mediation } \\
\hline
\end{tabular}

1- Direct effect before mediation (Extent of ABC Use $\longrightarrow$ Acceptance) is significant.

2- Both indirect paths (Extent of Use $\longrightarrow$ ABC Benefits \& ABC Benefits $\longrightarrow$ Acceptance) are significant.

3- The coefficient of the direct effect is reduced when the mediator (Reported ABC Benefits) entered the model but still significant.

The results presented in Table 4 illustrate that the direct effect of Extent of ABC Use on User Acceptance, before the inclusion of the mediator to the model, is significant. The P-Value of the direct effect is significant at $P<0.001$. When the mediator is inserted into the model, the coefficient of the direct effect is reduced from $(0.442)$ to $(0.278)$. However, the direct effect remained significant $(P=$
0.003 ) even after the mediator was interned to the model.

Given both indirect paths; Extent of $\mathrm{ABC}$ Use on Reported $\mathrm{ABC}$ Benefits $(\mathrm{P}<0.001)$ and Reported ABC Benefits on User Acceptance $(\mathrm{P}<0.01)$ are significant, and the coefficient of the direct effect is reduced when the mediator was interned to the model, the partial mediation is 
established and therefore, Hypothesis (5) is supported.

\subsubsection{User Acceptance of ABC System Mediates the Effect of the Magnitude of ABC Benefits on the Intention to Retain the System.}

The positive and significant effect of ABC Reported Benefits on User Acceptance has been stated in the previous section. Hence, to test for the mediation role of User Acceptance of $\mathrm{ABC}$ System in the relationship between the magnitude of $\mathrm{ABC}$ benefits and the intention to retain the system, the effect of User Acceptance on the Intention to Retain the System must be significant. The results presented in Table 3 show that the actual beta estimate for the effect of User Acceptance on the Intention to Retain the System is (0.130) with a standard error of about (0.044), a critical ratio of (2.934), and a P-value of (0.003). The P-Value indicates that the effect of User Acceptance on the Intention to Retain the System is significant at $P<0.01$ (The probability of getting a critical ratio as large as 2.934 in absolute value is .003). In other words, the regression weight for User Acceptance in the prediction of Intention to Retain the System is significantly different from zero at the 0.01 level (two-tailed). Hence, the results support Hypothesis (6).

The results presented in Table 5 illustrate that the direct effect of $\mathrm{ABC}$ Reported Benefits on Intention to retain $A B C$, before the inclusion of the mediator to the model, is significant. The P-Value of the direct effect is significant at $P<0.05$. When the mediator is inserted into the model, the direct effect is reduced and becomes insignificant, $\mathrm{P}=0.251$, implying that the regression weight is not significantly different from zero at the 0.05 level (two-tailed).

Since the coefficient of the direct bath has been reduced (from significant to insignificant) after the mediator interned to the model and both indirect paths (ABC Reported Benefits on User Acceptance and User Acceptance on the Intention to Retain the System) are significant at $(P<0.05)$ each, the full mediation is proved and consequently, Hypothesis (7) supported.

Table 5. Acceptance mediating the effect of "ABC Benefits" on the "Intention to Retain ABC"

\begin{tabular}{|c|c|c|c|c|c|c|c|c|}
\hline DVs & Path & IVs & $\begin{array}{l}\text { Standardiz } \\
\text { ed } \\
\text { Estimate }\end{array}$ & $\begin{array}{l}\text { Regression } \\
\text { Estimate }\end{array}$ & S.E. & C.R. & $\begin{array}{c}\mathrm{P}- \\
\text { value }\end{array}$ & Result \\
\hline \multicolumn{9}{|c|}{ Direct effect before mediation: } \\
\hline Intention to retain $\mathrm{ABC}$ & $<--$ & ABC Benefits & .307 & .033 & .015 & 2.228 & .026 & Significant \\
\hline \multicolumn{9}{|c|}{ Direct effect after mediation: } \\
\hline Intention to retain $\mathrm{ABC}$ & $<--$ & ABC Benefits & .159 & .017 & .015 & 1.147 & .251 & Insignificant \\
\hline \multicolumn{9}{|l|}{ Indirect effect: } \\
\hline Acceptance & $<--$ & ABC Benefits & .367 & .124 & .040 & 3.078 & .002 & Significant \\
\hline Intention to retain $\mathrm{ABC}$ & $<---$ & Acceptance & .403 & .130 & .044 & 2.934 & .003 & Significant \\
\hline Test of Mediation: & \\
\hline \multirow{2}{*}{\multicolumn{9}{|c|}{$\begin{array}{ll}1- & \text { Direct effect before mediation (ABC Benefits } \longrightarrow \text { the Intention to retain } \mathrm{ABC} \text { ) is significant. } \\
\text { 2- } & \text { Both indirect paths }(\mathrm{ABC} \text { Benefits } \longrightarrow \text { Acceptance \& Acceptance } \longrightarrow \text { Intention to retain } \mathrm{ABC} \text { ) are } \\
\text { significant. }\end{array}$}} \\
\hline & & & & & & & & \\
\hline $\begin{array}{l}\text { 3- The coefficient o } \\
\text { significant. }\end{array}$ & & effect is reduce & hen the med & tor (Acceptan & & & & \\
\hline
\end{tabular}

4.2.3 User Acceptance of ABC System Mediates the Effect of the Extent of ABC Use on the Intention to Retain the System.

The results displayed in Table 3 reveal that the Effect of the Extent of $\mathrm{ABC}$ Use on User Acceptance is significant. The actual beta estimate for the effect is $(0.278)$ with a standard error of about (0.092), a critical ratio of (3.005). The PValue of (0.003) indicates that the effect of Extent of $\mathrm{ABC}$ Use on User Acceptance is significant at
$P<0.01$ (The probability of getting a critical ratio as large as 3.005 in absolute value is .003). In other words, the regression weight for Extent of $\mathrm{ABC}$ Use in the prediction of User Acceptance is significantly different from zero at the 0.01 level (two-tailed). Accordingly, Hypothesis (8) is supported.

The second direct effect in this triangulated relationship (the effect of User Acceptance on the Intention to Retain the System) is significant as stipulated in the previous section. The results presented in Table 6 demonstrate that the direct 
effect of the Extent of $\mathrm{ABC}$ Use on Intention to Retain $\mathrm{ABC}$, before the inclusion of the mediator to the model, is significant, $\mathrm{P}<0.001$. When the mediator is inserted into the model, the direct effect is reduced and becomes insignificant, $\mathrm{P}=0.602$. The significance of the two indirect paths and the change of the direct path significance level confirm the mediating role of User Acceptance in the relationship between the extent of $\mathrm{ABC}$ use and the intention to retain the system. Thus, Hypothesis (9) is

Table 6. Acceptance mediating the effect of "Extent of ABC Use" on the "Intention to Retain ABC"

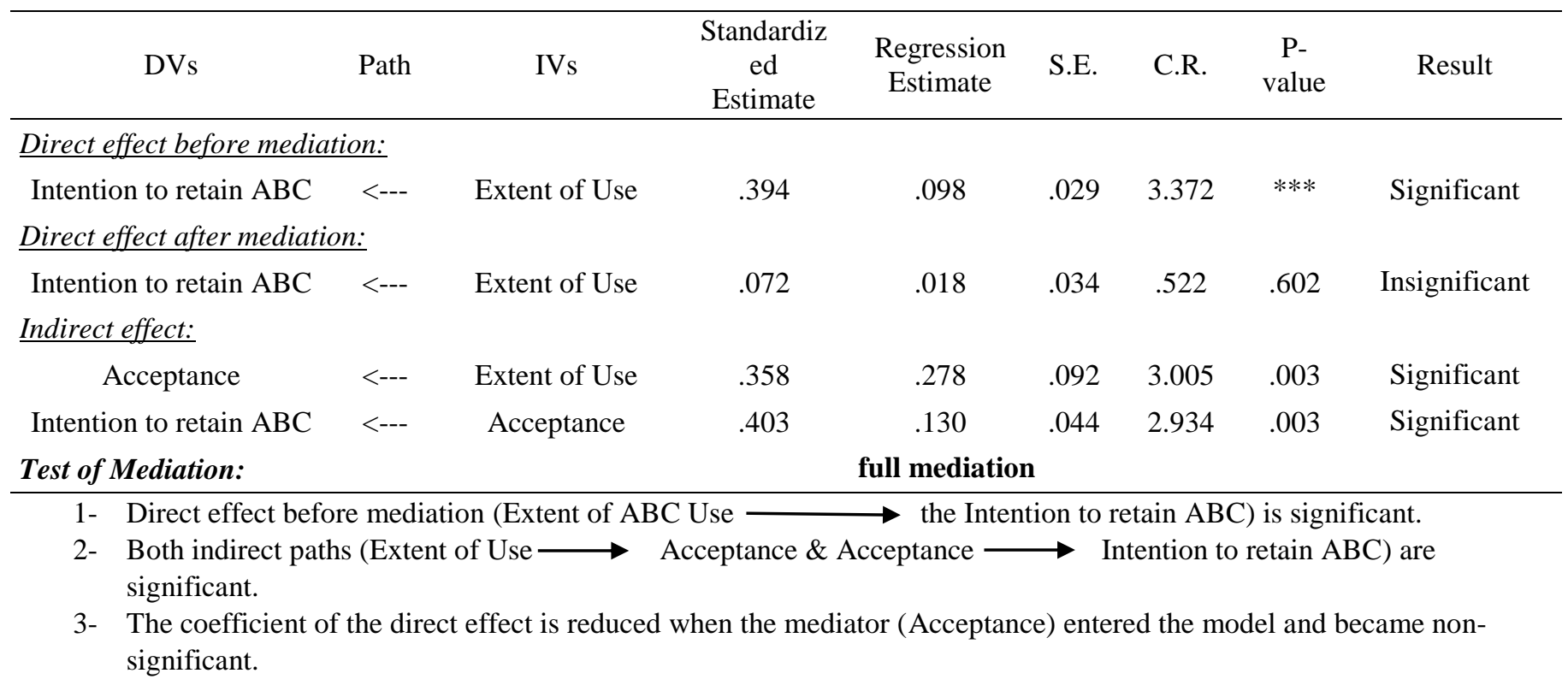

\section{Discussion and Conclusion}

$\mathrm{ABC}$ is a high-profile accounting information system and managerial accounting innovation. While the high cost of $\mathrm{ABC}$ system implementation has refrained a significant number of companies from its adoption [21, 25], a large number of other companies have adventured and shifted from the use of traditional costing systems to the use of ABC. However, not all companies were successful in implementing the $\mathrm{ABC}$ system $[9,15]$ and not all companies yield the expected pre-implementation benefits [40]. Users (departmental levels) resistance in many cases was the main obstacle for the wide application of the system and its success.

The proposed model by this study explains how user /staff or departments' resistance to $\mathrm{ABC}$ implementation can be reduced. Moreover, this study provides evidence on the acceptance of $\mathrm{ABC}$, as a managerial accounting system, by various users/departments as a result of the system usage rather than merely the user-perceived usefulness or ease of use. The findings of this study indicate that when $\mathrm{ABC}$ is widely used and integrated within organizational activities, operational and other nonaccounting departments realize the benefits that $\mathrm{ABC}$ provides and get more familiar with the system ending up with better acceptance and satisfaction. The acceptance of the ABC system by various departments facilitates the smooth implementation, optimize the value-added from the system, and reduce the cost associated with its implementation. Hence, the chance of the abandonment of the system is reduced to the minimal level which is reflected by the robust intention at the organizational level to retain the system and continue using it.

The findings showed that the extent of $\mathrm{ABC}$ use by surveyed companies is highly variable. Some companies use the $\mathrm{ABC}$ as a comprehensive information system that is integrated with all other financial, administrative, and operational systems. Others reported a partial use of $\mathrm{ABC}$ as a complementary system that works to aid other systems or to supplement them. Companies that used the $\mathrm{ABC}$ system for cost management, budgeting, pricing, customer profitability analysis, and performance measurement have reported more benefits when compared to those companies who use $\mathrm{ABC}$ for product cost determination only.

Companies with greater use of $\mathrm{ABC}$ have reported an increase in their profits. The increase in the firms' profit from $A B C$ implementation is due to 
the activity analysis that $\mathrm{ABC}$ provides to managers which enables them to reduce the number of activities performed (by eliminating non-value added activities) in addition to the increase of the efficiency of the activities performed. Hence, managers can do more business with the same activities by exploiting unused capacity to increase revenue without a mutual increase in resource spending which increases the net profit of the firms. Similar findings were revealed by Maiga and Jacobs [26] who found a positive and significant relationship between the extent of $\mathrm{ABC}$ use and profitability indirectly through the intervening variables of plant operational performance named; improved quality, cycle time, and cost.

$\mathrm{ABC}$ provides more benefits related to profit through customer profitability analysis. Companies have used this analysis to review the profits of customers and make strategic decisions related to pricing, services, distribution, promotions, and financing policies. Companies indicated many other realized benefits from $\mathrm{ABC}$ implementation such as enhancement of operational excellence, cost control improvement, more accurate product and service costs, assistance in cost reduction efforts, improved analysis of products and services profitability, better overhead cost allocation, provision of more accurate and timely information for decision making, improved analysis of profitability, and identification of non-value-added activities.

When $A B C$ is used on an organization-wide basis, more departments and employees are exposed to its functions and consequently acquire more experience with its operations and outcomes. Familiarity with the ABC system and the realized benefits enforce the acceptance of its implementation especially by non-financial departments who are usually less knowledgeable with accounting systems and thus have a lower level of pre-implementation appreciation. The wide acceptance of the $A B C$ information system yields a higher level of satisfaction that is reflected by the intention of the concerned level of management to retain the $\mathrm{ABC}$ and utilize its outputs for various decision-making purposes.

For ABC implementation success, the decisionmakers at the organizational level must consider the involvement of non-accounting personnel in designing the project, gathering data, and using information for decision making. Non-accounting managers' involvement will help in reducing their personnel resistance, facilitate user acceptance, and secure commitment by their employees. Furthermore, The ABC team composition should be cross-functional and should include employees from various departments to help in sharing experience and knowledge within the team.

This study contributes to the body of research by investigating the post-implementation acceptance of a managerial accounting system based on user experience which is in contrast to the vast majority of previous research that examines the preimplementation acceptance of the accounting systems based on users' perception. Further, this study explains the acceptance of a managerial accounting system at the organizational level through department-wise acceptance (rather than individual user) with a focus on the non-financial departments' acceptance and top management decision to retain the system. The results of this study illustrate a useful approach for companies' management that are planning to adopt a new accounting system to facilitate the acceptance of various internal stockholders and obtain the targeted benefits from the system. The low response rate of the survey and the investigation of an individual accounting system are the obvious limitations of this study. Future research could investigate the acceptance of managerial accounting systems as a package rather than an individual system.

\section{References:}

[1] Bhattacherjee A, Davis CJ, Connolly AJ, Hikmet N. User response to mandatory IT use: A coping theory perspective. European Journal of Information Systems. 2018;27(4):395-414.

[2] Hirschheim R, Newman M. Information systems and user resistance: theory and practice. The Computer Journal. 1988;31(5):398-408.

[3] Koh CE, Prybutok VR, Ryan SD, Wu Y. A model for mandatory use of software technologies: An integrative approach by applying multiple levels of abstraction of informing science. Informing Science. 2010;13.

[4] Sykes TA, Venkatesh V, Johnson JL. Enterprise system implementation and employee job performance: Understanding the role of advice networks. MIS quarterly. 2014;38(1):5172.

[5] Hwang Y, Al-Arabiat M, Shin D-H. Understanding technology acceptance in a mandatory environment: A literature 
review. Information Development. 2016;32(4):1266-83.

[6] Joshi K. A model of users' perspective on change: the case of information systems technology implementation. MIS quarterly. 1991:229-42.

[7] Laumer S, Eckhardt A. Why do people reject technologies: a review of user resistance theories. Information systems theory. 2012:63-86.

[8] Mahmud I, Ramayah T, Kurnia S. To use or not to use: Modelling end user grumbling as user resistance in preimplementation stage of enterprise resource planning system. Information Systems. 2017;69(3):164-79.

[9] Agbejule A. Motivation for activity based costing implementation. Journal of Accounting Organizational Change. 2006;2(2):42-73.

[10] Albalaki FMM, Abdullah Z, Kamardin H. The Influence of External Contingency Factors and Activity-Based Costing Implementation on Organizational Performance. Jurnal Pengurusan (UKM Journal of Management). 2019;55(9).

[11] Stratton WO, Desroches D, Lawson RA, Hatch T. Activity-based costing: is it still relevant? Management accounting quarterly. 2009;10(3):31.

[12] Malmi T. Activity-based costing diffusion across organizations: an exploratory empirical analysis of Finnish firms. Accounting, organizations society. 1999;24(8):649-72.

[13] Innes J, Mitchell F. A survey of activitybased costing in the UK's largest companies. Management accounting research. 1995;6(2):137-53.

[14] Argyris C, Kaplan RS. Implementing new knowledge: The case of activity-based costi. Accounting horizons. 1994;8(3):83.

[15] Jarrar NSb, Smith M, Dolley CJMaj. Perceptions of preparers and users to accounting change: a case study in an Australian university. Managerial auditing journal. 2007;22(2):80-94.

[16] Duh RR, Lin TW, Wang WY, Huang CH. The design and implementation of activity- based costing. International
Journal of Accounting Information Management. 2009.

[17] Lee C-L, Yen DC, Peng K-C, Wu H-C. The influence of change agents' behavioral intention on the usage of the activity based costing/management system and firm performance: The perspective of unified theory of acceptance and use of technology. Advances in Accounting. 2010;26(2):31424.

[18] Innes J, Mitchell F, Sinclair D. Activitybased costing in the UK's largest companies: a comparison of 1994 and 1999 survey results. Management accounting research. 2000;11(3):349-62.

[19] Kennett DL, Durler MG, Downs A. Activity-based costing in large US cities: Costs \& benefits. The Journal of Government Financial Management. 2007;56(1):20.

[20] Souissi M. Activity-based costing approach: how it has been perceived in Japan. International Journal of Management. 2002;19(2):343.

[21] Cohen S, Venieris G, Kaimenaki E. ABC: adopters, supporters, deniers and unawares. Managerial auditing journal. 2005;20(9):981-1000.

[22] Maelah R, Ibrahim DN. Activity based costing (ABC) adoption among manufacturing organizations-the case of Malaysia. International Journal of Business Society. 2006;7(1):70-101.

[23] McGowan AS, Klammer TP. Satisfaction with activity-based cost management implementation. Journal of management accounting research. 1997;9:217.

[24] Chenhall RH. The role of cognitive and affective conflict in early implementation of activity- based cost management. ehavioral research in accounting. 2004;16(1):19-44.

[25] Liu LY, Pan F. The implementation of Activity-Based Costing in China: An innovation action research approach. The British Accounting Review. 2007;39(3):249-64.

[26] Maiga AS, Jacobs FA. Extent of ABC use and its consequences. Contemporary 
Accounting Research. 2008;25(2):533660.

[27] Davis FD. Perceived usefulness, perceived ease of use, and user acceptance of information technology. MIS quarterly. 1989:319-40.

[28] Salanova M, Grau RM, Cifre E, Llorens S. Computer training, frequency of usage and burnout: the moderating role of computer self-efficacy. Computers in Human Behavior. 2000;16(6):575-90.

[29] Silaban A. The integration of technology acceptance model with the uses and gratification theory toward the intention to use accounting information technology. QUALITY Access to Success. 2018;19(165):143-9.

[30] Kraus N, Kraus K. Digitalization of business processes of enterprises of the ecosystem of Industry 4.0: virtual-real aspect of economic growth reserves. WSEAS Transactions on BusinessEconomics. 2021;18:569-80.

[31] Shields MD. An empirical analysis of firms' implementation experiences with activity-based costing. Journal of management accounting research. 1995;7(1):148-65.

[32] Major M, Hopper T. Managers divided: Implementing $\mathrm{ABC}$ in a Portuguese telecommunications company. Management Accounting Research. 2005;16(2):205-29.

[33] Nolan PM. Critical success factors for implementing an enterprise-wide $\mathrm{ABC}$ solution. Journal of Performance Management. 2004;17(3):15.

[34] Andersson H, Tuddenham P. Reinventing IT to support digitization. Mckinsey insights

publicationshttp://wwwmckinseycom/Insig hts/Business_Technology/Reinventing_IT to_support_digitization. 2014.

[35] Shkurti R, Manoku E. Factors of Success in Implementation of Enterprise Resource Planning Systems. WSEAS Transactions on Business Economics. 2021;18:108493.
[36] PanoramaConsultingSolutions. The 2021 ERP Report. Panorama Consulting Solutions; 2021.

[37] Narayanan V, Sarkar RG. The Impact of Activity- Based Costing on Managerial Decisions at Insteel Industries-A Field Study. Journal of Economics Management Strategy. 2002;11(2):25788.

[38] Drennan L, Kelly M. Assessing an activity-based costing project. Critical Perspectives on Accounting. 2002;13(3):311-31.

[39] Al-Dhubaibi A. Optimizing the value of activity based costing system: The role of successful implementation. Management Science Letters. 2021;11(1):179-86.

[40] Chong VK, Cable R. A Study on the Implementation of an Activity- Based Costing (ABC) System in an Australian Oil and Gas Company. Asian Review of Accounting. 2002.

\section{Creative Commons Attribution License 4.0} (Attribution 4.0 International, CC BY 4.0)

This article is published under the terms of the Creative Commons Attribution License 4.0 https://creativecommons.org/licenses/by/4.0/deed.en US 